\title{
ERRATUM
}

\section{A Pharmacokinetic Model-Independent Approach for Estimating Dose Required to Give Desired Steady-State Trough Concentrations of Drug in Plasma}

\author{
John T. Slattery ${ }^{1}$
}

Received May 23, 1980

In this report (Vol. 8, No. 1, 1980, pp. 105-110), a reference to an equation (1) similar to the one used was overlooked. The previously reported equation related minimum steady-state concentration of a drug in plasma to maintenance dose through a proportionality factor $p F / V_{d}$ and the hybrid rate constant $\beta$. It was suggested that $\beta$ be estimated for the individual patient in some manner, such as from a correlation between $\beta$ and endogenous creatinine clearance. This would reduce the error in estimating maintenance dose to two sources: the interindividual variability in the proportionality factor $p F / V_{d}$ and in the relationship between $\beta$ and creatinine clearance. No discussion of obtaining patient-specific estimates of $p F / V_{d}$ was presented. The author regrets the omission of this reference.

\section{REFERENCE}

1. John G. Wagner. Fundamentals of Clinical Pharmacokinetics, Drug Intelligence Publications, Hamilton, Ill., 1975, p. 136.

${ }^{1}$ Department of Pharmaceutics, School of Pharmacy BG-20, University of Washington, Seattle, Washington 98195. 